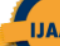

International Journal of Advanced Academic Research (Arts, Humanities and Education) | ISSN: 2488-9849 Vol. 6, Issue 10 (October, 2020) | www.ijaar.org

\title{
TEACHERS' TEACHING METHODS AND STUDENTS' ACADEMIC PERFORMANCES IN IBARAPA EAST LOCAL GOVERNMENT AREA SECONDARY SCHOOLS
}

\author{
OKE, ABIODUN ADEWOLE \\ DEPARTMENT OF CURRICULUM AND INSTRUCTIONS, \\ SCHOOL OF GENERAL EDUCATION, \\ THE COLLEGE OF EDUCATION, \\ LANLATE, OYO STATE, NIGERIA. \\ E-Mail: okeabioduna@yahoo.com. GSM: +2348053029049, \\ $+2349030623040 \&+2348039363786$.
}

\begin{abstract}
This study was to investigate the differential relationship between teaching methods and students' academic performances in Ibarapa East Local Government area Secondary schools. A sample of 100 students drawn from the Sciences, Commercial and Arts departments of all the secondary schools in the local government area were used for the study. Using the inferential statistics, students' assessment test scores were derived from the internal class test prepared by some Measurement and Evaluation teachers. The differential relationship of the three major teaching methods on students' academic performances was analysed using the General Linear Model based univariate ANOVA technique. The F(2, 107) statistic ( $=10.13 ; p<0.05$ level of significance) and the Tukey HSD post-hoc results indicate that there is significant differences in the relationship between the three teaching methods and students' academic performances. The mean scores results demonstrate that teacherstudents interactive method was the most effective teaching method, followed by studentcentered method while the teacher-centered approach was the least effective teaching method. Among the recommendations suggested were: New approaches to teaching learning processes which connect to the learning needs of students should be put in place in order to reduce the menace of students performing poorly in school and eventually dropping out of studies. Student-centered learning environment should be encouraged in our secondary schools because it produces higher-level learning outcomes more efficiently than a traditional teacher-centered environment. There should be no bias in the selection of teaching methods by teachers in areas in which they possess exclusive monopoly knowledge to improve students' academic performances in our secondary schools. Teachers should create an atmosphere conducive for learning in order to enhance the development of students' learning experiences.
\end{abstract}

KEYWORDS: Teacher-centered, student-centered, teacher-student interactive and performance. 


\section{Introduction}

The roles the teachers' teaching methods play in a school system and in the lives of the students cannot be overstressed. The primary role it plays at any level of education is to enhance a fundamental change in the learners' behaviour (Tebabal \& Kahssay, 2011). Transferring knowledge requires teachers to use the appropriate teaching method and pedagogy that best suits the learner and suit the objectives and desired outcomes. Most of the traditional methods were teacher- centered with no activity for the learners making them to be passive and therefore obtaining knowledge from the teacher without building their engagement level with the subject matter, the approach is not practical oriented, more theoretical and leads to memorization. Until recently, questions about the influence of effective teaching methods on students' learning have consistently raised considerable interest in educational research. Moreover, research on teaching and learning constantly endeavours to examine the extent to which different teaching methods enhance growth and development in students' learning.

Regrettably, poor academic performance by the students in Nigeria is fundamentally linked to application of ineffective teaching methods by teachers to impact knowledge to learners (Adunola, 2011). Ayeni (2011) also perceived teaching as a process that involves bringing about desirable changes in learners so as to achieve specific outcomes and in order for the method used for teaching to be effective, he maintains that teachers need to be conversant with numerous teaching strategies that take recognition of the magnitude of complexity of the concepts to be covered.

Adunola (2011) classified teaching methods that are available to teachers in a classroom situation, into four broad headings. These are; teacher-centred methods, learner-centred methods, content-focused methods and interactive/participative methods. Other method is Enter Education

\section{(a) Instructor/Teacher Centred Methods}

Here, the teacher is seen playing the role of being a master of the subject matter. The teacher is looked upon by the learners as an expert or an authority. Learners on the other hand are presumed to be passive and copious recipients of knowledge from the teacher. Examples of such methods are expository or lecture methods - which require little or no involvement of learners in the teaching process. It is also for this lack of involvement of the learners in what they are taught, that such methods are called "closed-ended".

\section{(b) Learner - Centred Methods}

In learner-centred methods, according to Ayeni (20011), the teacher/instructor is both a teacher and a learner at the same time. He said further that the teacher plays the role of a learner as well "so that in his classroom extends rather than constricts his intellectual horizons". The teacher also learns new things everyday which he/she didn't know in the process of teaching. The teacher, "becomes a resource rather than an authority". Examples of learner-centred methods are discussion method, discovery or inquiry based approach and the Hill's model of Learning Through Discussion (LTD). 


\section{(c) Content - Focused Methods}

In this category of methods, both the teacher and the learners have to fit into the content that is taught. Generally, this means the information and skills to be taught are regarded as sacrosanct or very important. A lot of emphasis is laid on the clarity and careful analyses of content. Both the teacher and the learners cannot alter or become critical of anything to do with the content. An example of a method which subordinates the interests of the teacher and learners to the content is the programmed learning approach (Ayeni, 2011).

\section{(d) Interactive/Participative Methods}

This fourth category borrows a bit from the three other methods without necessarily laying emphasis unduly on either the learner, content or teacher. These methods are driven by the situational analysis of what is the most appropriate thing for us to learn/do now given the situation of learners and the teacher. They require a participatory understanding of varied domains and factors.

Specifically, Adunola (2011) further stated that, this can be considered at specific levels in the course of classroom instructions which will bring about good students' academic performances. It is however, important to note that the choice of any form of methods should not be arbitrary, but needs to be governed by the criteria we have already examined. At the same time each method is not fool-proof, but has its own advantages and disadvantages. That is why the researcher recommends the use of complementary methods rather than one method.

The first method to be mentioned is Lecture method. A lecture is an oral presentation of information by the instructor. It is the method of relaying factual information which includes principles, concepts, ideas and all theoretical knowledge about a given topic. Ayeni (2011) opined that "in a lecture the instructor tells, explains, describes or relates whatever information the trainees are required to learn through listening and understanding". It is therefore seen as an example of teacher-centred. The instructor is very active, doing all the talking. Trainees on the other hand are very inactive, doing all the listening. Despite the popularity of lectures, the lack of active involvement of trainees limits its usefulness as a method of instruction. The lecture method of instruction is recommended for trainees with very little knowledge or limited background knowledge on the topic. It is also useful for presenting an organised body of new information to the learner. To be effective in promoting learning, the lecture must involve some discussions and, question and answer period to allow trainees to be involved actively.

As stated earlier, during the lecture, the trainees merely listen to the instructor. It is therefore very important to consider the attention span of trainees when preparing a lecture. The attention span is the period of time during which the trainees are able to pay full attention to what the instructor is talking about. It is estimated to be $15-25$ minutes only. It is difficult to hold the trainees attention for a long period of time and careful preparation of lectures is very necessary (Ayeni, 2011).

The instructor should have a clear, logical plan of presentation. He/she should work out the essentials of the topic, organise them according to priorities and logical connections, and 
establish relationships between the various items. Careful organisation of content helps the trainees to structure and hence, to store or remember it. When developing a theme in a lecture, the instructor should use a variety of approaches. Ayeni (2011) stated that "useful principle in any instruction is to go from the KNOWN to UNKNOWN; from SIMPLE to COMPLEX, or from PARTS to a WHOLE". Knowing the trainees and addressing their needs and interests is very important. For example, in explaining technical processes the instructor should search for illustrations that will be familiar to the trainees. Unfamiliar technical words should be introduced cautiously. New terminologies should be defined and explained and examples given. In order to gain and focus the attention of trainees, the instructor should be adequately prepared, fluent in his/her presentation and should use various teaching aids and illustrations such as charts, transparencies, codes and even the real objects during presentation. Question and Answer periods should be included in the lecture.

Lecture method has the following characteristics according to Hightower (2011):

A good lecture should not be too long as to exceed the trainees' attention span (up to 25 minutes).

A good lecture should address a single theme.

In a good lecture technical terms are carefully explained.

Familiar examples and analogies are given.

A good lecture establishes fluency in technical content.

A good lecture uses illustrations and examples.

A good lecture builds on existing knowledge.

A good lecture employs a variety of approaches.

Another method that is worthy of mentioning is the discussion method. This, according to Hightower (2011), "involves two-way communication between participants. In the classroom situation an instructor and trainees all participate in discussion". During discussion, the instructor spends some time listening while the trainees spend sometimes talking. The discussion is, therefore, a more active learning experience for the trainees than the lecture. A discussion is the means by which people share experiences, ideas and attitudes. As it helps to foster trainees' involvement in what they are learning, it may contribute to desired attitudinal changes. Discussion may be used in the classroom for the purpose of lesson development, making trainees apply what they have learnt or to monitor trainees learning by way of feedback.

He stated further that "in areas in which trainees already have some knowledge or experience, discussion may be used to develop the main points to be covered in a lesson. For example, in safety training many of the procedures and behaviour that should be observed can be established through discussion with trainees." Trainees can draw on their experience of working in workshops contract sites to contribute to the discussion. In discussing some issues, differences of opinion arise. The discussion can help to clarify the different points of 
view and may assist each trainee to define his or her own opinion. Used in this way, discussion may be more effective in motivating trainees than lectures. Trainees can see that some importance is attached to their contributions.

Discussion may also be applied or used, following a lecture or demonstration, to help trainees apply what they have learned. The instructor can ask questions that help trainees to relate concepts and principles to contexts that are familiar to the trainees or in which they will ultimately be needed. For example, following a lecture on "types of wood joint", the instructor may, lead a discussion directing trainees' attention to the places or pieces of furniture where each type is found, and the reasons for using one type than the other. Used in this way, discussion contributes to the transfer of learning.

The discussion method also provides an opportunity to monitor trainees learning. The answers provided by trainees and the questions they ask, reveal the extent and quality of learning taking place. Instructors can use this information to repeat or modify an explanation to improve learning. They can also provide feedback to trainees, thereby helping to reinforce learning that has taken place. Discussion used in this way should follow after other methods of classroom instruction such as lectures, demonstration or practice sessions.

Discussion sessions can be led by the instructor, or can take place in groups. In either case, the goal is to meet the lesson objectives by allowing the trainees to:

a) Relate relevant personal experiences or events which have occurred in the work setting.

b) Contribute ideas or personal opinions.

c) Apply what has been learned to familiar situations or solving problems.

d) Express what had been learned.

Whether the discussion is instructor led or takes place in groups, it must be guided by the instructor. It must be focused on the objectives of the lesson: it is the instructor's responsibility to see that the objectives are met. If it is not properly guided, a discussion can degenerate into a consideration of inappropriate or unimportant topics adding confusion rather than clarification to the lesson (Adunola, 2011).

Further still, demonstration method is another method that needs to be mentioned. Demonstration means any planned performance of an occupation skill, scientific principle or experiment. Ayeni (2011) says that "the most effective way to teach an occupational skill is to demonstrate it... one of the two most essential teaching skills is the ability to demonstrate; the other is the ability to explain. Both are vital to the success of either an operation lesson or an information lesson".

In preparation of the teacher for demonstration method, the teacher should:

$>$ Rehearse your presentation in advance of the lesson.

$>$ Anticipate any difficult steps, possible interruptions e.t.c.

$>$ Obtain all materials, tools, equipment, visual and teaching aids in advance and check their useful condition.

$>$ Have all materials within reach and conveniently arranged. 
$>$ Time the demonstration NOT to exceed 15 minutes.

$>$ Remove all extraneous materials; check lighting, visibility, student grouping, and proximity to electric, gas and water outlets.

$>$ Plan to use a skill or method to advantage; work from simple to complex, one step at a time.

While presenting, the teacher should:

$>$ Make sure all students can see and hear the lesson.

$>$ Be enthusiastic, professional, effective but not dramatic.

$>$ Relax; use any mishaps or humour to YOUR advantage.

$>$ Observe all safety rules and procedures.

$>$ Keep eye-contact with the class; ask and encourage class questions.

$>$ Explain WHY and HOW: use the techniques of SHOW and TELL.

$>$ Use a medial summary to strengthen your explanation.

The following precautions should be made by the teacher when using demonstration method:

Avoid interruptions; keep demonstration smooth and continuous.

Never demonstrate on a student's material.

Work towards one aim.

Allow time for possible student participation.

As the teacher is carrying out a demonstration method for the students, the teacher should:

$>$ Give a good performance. Remember that the trainees learn by your good example.

$>$ Explain each step or process as you proceed. Follow your lesson plan.

$>$ Make sure the trainees see the demonstration from the angle they will perform it themselves.

$>$ Be sure everyone can see and hear. Maintain eye contact.

$>$ Emphasise key points, and if possible prepare before-hand ask key questions as you go along and allow trainees to ask questions.

$>$ Observe all safety rules, precautions and procedures; and emphasise them.

$>$ Use proper instructions, aids such as chalkboard, charts, handouts e.t.c. to support your demonstration.

$>$ Provide for trainees participation where possible, during and after demonstration.

$>$ Demonstrate the correct way only. First impressions are important, therefore, make them correct ones.

$>$ Always summarise the steps and emphasise key points again.

After the teacher is done with the demonstration method, the teacher should:

$>$ Return all items used during demonstration to their storage places.

$>$ Make arrangements to have the trainees practice the skill as soon as possible in a practical class session.

Observe and analyse trainee(s) performance and correct mistakes.

$>$ Offer reinforcement where necessary.

$>$ Coach weak or slow trainees.

$>$ Check trainee's completed work for accurate performance and record.

$>$ Allow sufficient time interval before demonstrating another operation.

Similarly, another method of instruction is the buzz group. During a longer session, the plenary group can break into sub-groups to discuss one or two specific questions or issues. 
The room soon fills with noise as each sub-group 'buzzes' in discussion. If appropriate, after the discussion one member of each group can report its findings back to the plenary. Buzz groups can be in pairs, trios, or more depending on the activity. People turn to their neighbours for a quick buzz, or form larger groups of three or more. This allows almost every one to express an opinion. While they are buzzing, participants are able to exchange ideas and draw on their wide collective experience. It may provide a good opportunity for trainees to reflect on the content of a lecture. A good buzz session will generate many ideas, comments and opinion, the most important of which will be reported back (Hightower, 2011). The advantages this method has for the trainers are that, it helps the teachers to:

- Draw his breath

- Gauge the mood, by listening to some of the discussions

- Change pace of the session

- Encourage participants to reflect on what they have learnt and how they might apply it in their work.

The main obstacle using buzz sessions lie in unfamiliarity with their use, the time required, the need for leaders or facilitators within each sub-group, and the need to have tables and chairs arranged for quick and easy discussion.

Furthermore, another method that is worthy of mentioning is brainstorming. The purpose of a brainstorming session is to discover new ideas and responses very quickly. It is particularly a good way of getting bright ideas. It differs from the buzz groups discussion in that the focus is on generating as many ideas as possible without judging them. In this technique, all ideas are given equal credence. Participants are encouraged to let ideas flow freely, building on and improving from previous ideas. No idea, however crazy, should be rejected. These ideas are listed exactly as they are expressed on a board or flipchart, or written on bits of paper. The combination of swiftly generated ideas usually leads to a very animated and energising session. Even the more reserved participants should feel bold enough to contribute. The purpose of listing responses is to collect existing experiences and thoughts. It is useful to collect answers to questions when you expect much repetition in the responses.

After a brainstorm session, the ideas can be discussed further and evaluated, for example listing the best options in a systematic way. Ideas can be grouped and analysed so that they belong to the group rather than individuals. Unlike a buzz session, a brainstorm session can work well with a large group and usually takes less time. It is best to limit the time for plenary brainstorms, as you might lose the attention of some participants.

Role Plays is another method that should be mentioned. In role plays, participants use their own experiences to play a real life situation. When done well, role plays increase the participants' self-confidence, give them the opportunity to understand or even feel empathy for other people's viewpoints or roles, and usually end with practical answers, solutions or guidelines. Role plays are useful for exploring and improving interviewing techniques and examining the complexities and potential conflicts of group meetings. They help participants to consolidate different lessons in one setting and are good energisers (Hightower, 2011).

However, role plays can be time-consuming and their success depends on the willingness of participants to take active part. Some trainees may feel a role play is too exposing, threatening or embarrassing. This reluctance may be overcome at the outset by 
careful explanation of the objectives and the outcome. Some role plays can generate strong emotions amongst the participants. It is therefore essential that a role play is followed by a thorough debriefing. This provides the opportunity for the trainer and the participants to raise and assess new issues.

Other method that is worthy of mentioning is Enter Education. Enter Education is an instructional strategy/method which delivers purposefully selected educational contents to its audience through the means of entertainment with a view to effecting some changes in the behaviour of the recipients/learners. Atolagbe (2020) defined it "as any instructional media designed in order to educate through the use of entertainment". Simply put, it is the education delivered through entertainment in order to achieve more positive results.

Characteristics of Enter - Education according to Atolagbe (2020), include the following:

$>$ Enter Education uses, in most cases, drama, songs and fictions through the mass media.

$>$ It can be used in teaching all topics or themes at all levels.

$>$ It is practicable inside and outside the classroom.

$>$ It can be adopted for all categories of citizens.

$>$ It can be interactive just as it can also be passive.

The advantages are: Pervasive, popular, personal, participatory, passionate, persuasive, practical, profitability, proven effective. While the disadvantages may include: high cost, sourcing energy, getting the right type of designers, danger of misleading audience, dismisses the possible classroom social interaction, tendency to be abused or misused, possible difficulty in construction.

Research Objective: The primary objective of this study was to establish the relationship between different teaching methods and students' academic performances in Ibarapa East Local Government Secondary Schools.

Research Question: Are there any significant relationship between different teaching methods and students' academic performances in Ibarapa East Local Government Secondary Schools?

Null Hypothesis: The methods of teaching do not significantly influence students' academic performances in Ibarapa East Local Government Secondary Schools.

Research Design: The research design for this investigation was an experimental study. The independent variable was teaching methods and the dependent variable was students' academic performances.

Population and Sample: The population for this study were all secondary schools in Ibarapa East Local Government area of Oyo State and the sample consisted of one hundred $(n=100)$ students; from which $30 \%(n=30)$ were males and $70 \%(n=70)$ were females.

\section{Data}

The data for the study were generated from students' academic performance assessment test scores. The test was prepared by some teachers who are experts in measurement and evaluation and drawn from selected topics of inferential statistics; namely confidence interval 
estimation, hypothesis testing and chi-square distribution. The content validity of the test paper was ensured through moderation in line with the institutional academic quality assurance system. The test was prepared based on the course exit level outcomes.

Treatment: The sample was categorised into three groups; Group 1 comprised of Science class $(n=40)$ students, Group 2 comprised of Commercial class $(n=35)$ students and Group 3 encompassed Arts $(\mathrm{n}=25)$ students. During the teaching and learning process, teacher-student interactive, teacher-centered and student-centered methods were applied on the three groups; respectively.

Statistical Technique: The General Linear Model based univariate ANOVA technique was applied to examine the effectiveness of teaching methods on student academic performance; following the framework adopted by Cooper \& Cohn (1997):

$\mathrm{F}\left(\mathrm{y}_{\mathrm{ij}}, \mathrm{x}_{\mathrm{ij}}\right)_{<} \mathrm{C}$

where: $\mathrm{F}$ represents the function which transforms $\mathrm{x}$ into $\mathrm{y} ; \mathrm{y}$ denotes academic performance test score of the ith student in group $\mathrm{j}$; $\mathrm{x}$ represents the ith teaching method applied to group $\mathrm{j}$; and $\mathrm{C}$ denotes the positive scalar; which overall further reduces to:

$$
\mathrm{TS}_{\mathrm{ij}}=\varphi_{\mathrm{j}}+\varphi_{\mathrm{j}} \mathrm{TM}_{\mathrm{ij}}+\varepsilon_{\mathrm{ik}}--------------------------(2)
$$

where: TS represents academic performance test score of the ith student in group $\mathrm{j}$; TM denotes the teaching method applied on $\mathrm{i}^{\text {th }}$ student in group $\mathrm{j}$; and $\varphi_{\mathrm{j}}$ captures the effectiveness of the teaching method applied to a particular group.

The effectiveness of teaching methods was analysed using descriptive statistics and the ANOVA approach. Descriptive statistics were used to analyse the estimated marginal means, standard deviation and standard error estimates; while the ANOVA Tukey HSD post hoc test was applied to examine whether any significant differences existed between the students' performance mean scores of the three teaching methods.

\section{RESULTS AND INTERPRETATION}

The outcome variable was students' academic performance assessment test scores generated from the internal test prepared by some secondary school teachers. Data were analyzed using descriptive statistics to examine the profile of the sample. From the sample of hundred students $(n=100) ; 70 \%$ were females and $30 \%$ were males. Leaners' performance assessment test scores were recorded in the high, moderate and low band categories; upon which $30 \%$ $(n=28), 67.0 \%(n=70)$, and $2.8 \%(n=2)$ were in the low, moderate and high classes; respectively. The test results were categorically scaled as: $[75-100 \%]=$ high; $[50-74 \%]=$ moderate; and [0-49\%] = low (Figure 1). 


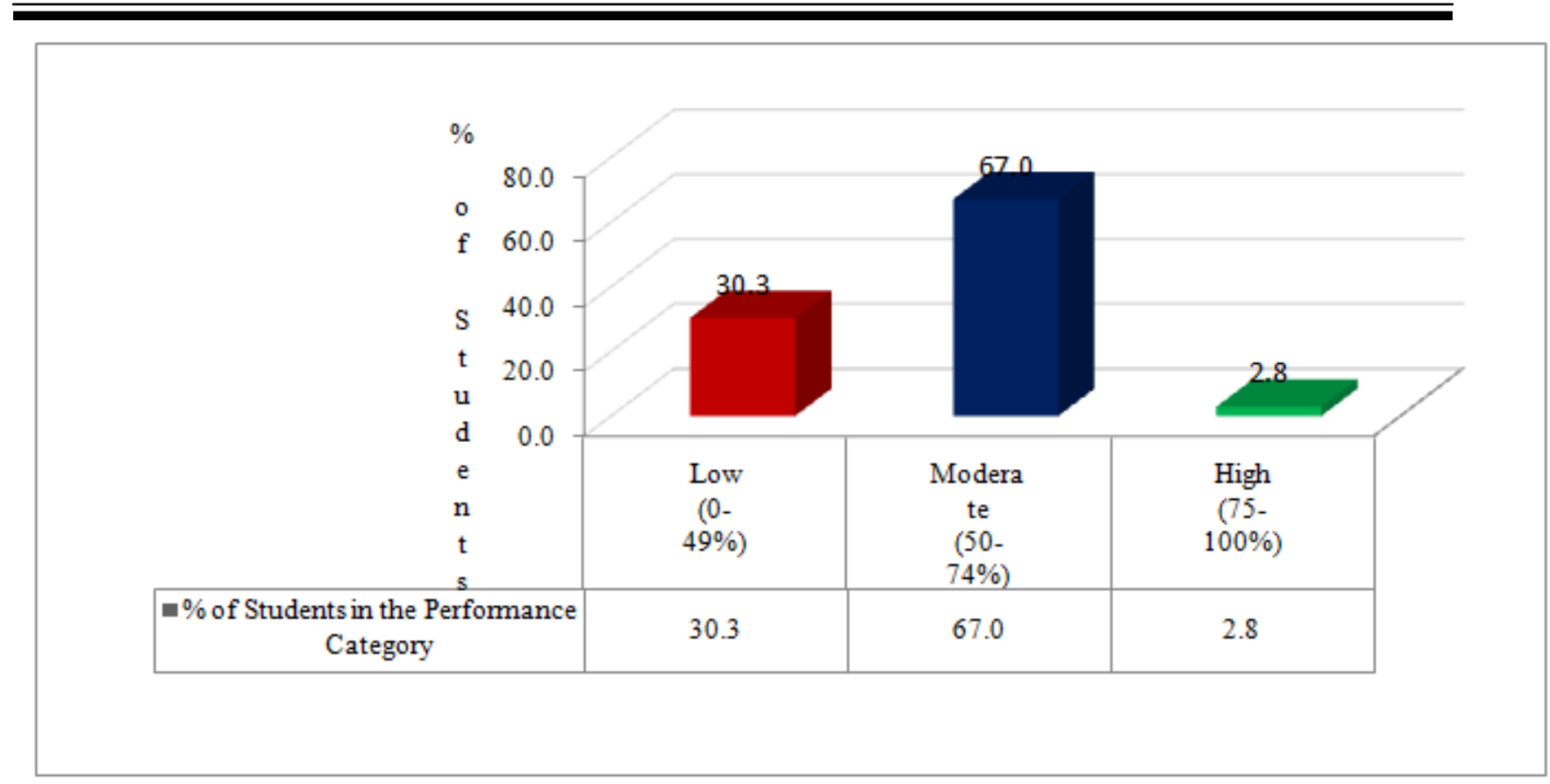

Figure 1: Students' Academic Performance Assessment Test Scores

\begin{tabular}{|c|c|c|c|c|c|}
\hline \multirow{2}{*}{$\begin{array}{l}\text { Performance Assessment } \text { Test } \\
\text { Scores Based On Teaching } \\
\text { Method: }\end{array}$} & \multirow{2}{*}{$\begin{array}{l}\text { Estimated } \\
\text { Mean }\end{array}$} & \multirow{2}{*}{$\begin{array}{l}\text { Standard } \\
\text { Deviation }\end{array}$} & \multirow{2}{*}{$\begin{array}{l}\text { Standard } \\
\text { Error }\end{array}$} & \multicolumn{2}{|c|}{0.05 Confidence Interval } \\
\hline & & & & L.B. & U.B \\
\hline $\begin{array}{l}\text { Teacher-Student Interactive }(n=40) \\
\text { Teacher-Centered }(n=25) \\
\text { Student-Centered }(n=35)\end{array}$ & $\begin{array}{l}1.98 \\
1.26 \\
1.74\end{array}$ & $\begin{array}{l}0.488 \\
0.480 \\
0.428\end{array}$ & $\begin{array}{l}0.084 \\
0.089 \\
0.076\end{array}$ & $\begin{array}{l}1.844 \\
1.196 \\
1.754\end{array}$ & $\begin{array}{l}2.019 \\
1.675 \\
1.960\end{array}$ \\
\hline
\end{tabular}

Based on the teaching methods applied, the estimated marginal mean estimates reveal that teacher-students interactive approach produced the high mean score (mean=1.98), followed by the student-centered approach $($ mean $=1.74)$ and the lowest mean score $($ mean=1.26) was recorded for the teacher-centered approach. The mean estimates for all the three teaching methods fall within the 0.05 confidence interval bands.

The results reveal that combining both teacher-centered and student-centered teaching methods in teaching learners is the most effective approach that produces best student results. This result is consistent with the findings by Wiggins (1987) who reported that interaction between the teacher and students during the teaching and learning process encourages the students to search for knowledge rather than the lecturer monopolizing the transmission of information to the learners. The estimated mean score $(m e a n=1.74)$ recorded for the studentcentered approach is marginally lower than that of the teacher-student interactive approach. This indicates that student-centered methods are also an effective teaching approach, which is consistent with the findings by Lindquist (1995) who indicated that student-centered methods 
promote greater mastery of the subject matter than centralizing the flow of knowledge as a one way channel from the lecturer to the students. Application of teacher-centered methods produced results that were significantly lower (mean=1.26) comparative to those derived when using teacher-students interactive and student-centered approaches. This confirms the findings by Hake (1998) who reported that students' little or no active involvement in the learning process could lead them to perform poorly in their academics and that of Lei, (2007) about the relationship between teacher-student interactive and student-centered approaches and pupils' achievement in comparison with the usage of traditional instruction showed that teacher-student interactive and student-centered approaches have a more positive impact on pupils' achievement than traditional methods. This difference in achievement could be attributed to the fact that teacher-student interactive and student-centered based teachinglearning applications are considered an effective alternative to traditional teaching methods because it presents students with unlimited opportunities to demonstrate the mastery of contents taught.

\section{Table 2: Test of Between - Subjects Effects}

The results derived from the tests of between subjects effects indicated significant differences between performance test scores of the three teaching methods

\begin{tabular}{|l|l|l|l|l|l|}
\hline Source & $\begin{array}{l}\text { Type III Sum of } \\
\text { Squares }\end{array}$ & Df & Mean Square & F - Statistics & Significance \\
\hline Corrected & 4.460 & 3 & 2.225 & 10.135 & 0.000 \\
Model Intercept & 286.080 & 1 & 286.080 & $1.302 \mathrm{E} 3$ & 0.000 \\
Teaching & 4.450 & 3 & 2.225 & 10.135 & 0.000 \\
Methods & 23.293 & 107 & 0.220 & & \\
Error & 352.000 & 109 & & & \\
Total & 28.733 & 108 & & & \\
Corrected Total & \multicolumn{5}{|l|}{} \\
\multicolumn{2}{|l|}{ a. R Squared $=0.156$ (Adj. R Squared =0.155) } & & \\
\hline
\end{tabular}

The performance assessment scores of students differed significantly among the three teaching methods $(\mathrm{F}(2,107)$ statistic $(=10.13)$ at 0.05 level of significance $)$. Together with the SS, the corrected total of 27.743 indicates variability in the performance assessment test score variable. The R-Squared (0.156) equals the SS (Teaching Method)/SS (Corrected Total) $=4.460 / 28.733$. To detect which of the three teaching methods assessment mean scores differed significantly from one another; the Tukey HSD post hoc test was applied for the analysis (Table 3). In the light of the number of comparisons that were made, the Tukey posthoc approach was applied because of its power to control for alpha inflation. 
Table 3: Tukey HSD post-hoc Test

\begin{tabular}{|c|c|c|c|c|c|}
\hline \multirow[t]{2}{*}{$\begin{array}{l}\text { (I) Teaching Method (J) Teaching } \\
\text { Method }\end{array}$} & \multirow[t]{2}{*}{ Mean Diff (I-J) } & \multirow[t]{2}{*}{ Std. Error } & \multirow[t]{2}{*}{ Sig. } & \multicolumn{2}{|c|}{$\begin{array}{ll}0.05 & \text { Confidence } \\
\text { Interval } & \end{array}$} \\
\hline & & & & LB & UB \\
\hline $\begin{array}{l}\text { Teacher-Centered Student-Centered } \\
\text { Teacher-Student Interactive }\end{array}$ & $\begin{array}{l}-0.419^{*} \\
-0.610^{*}\end{array}$ & $\begin{array}{l}0.111 \\
1.126\end{array}$ & $\begin{array}{l}0.111 \\
1.126\end{array}$ & $\begin{array}{l}-0.62 \\
-0.69\end{array}$ & $\begin{array}{l}-0.14 \\
-0.13\end{array}$ \\
\hline $\begin{array}{l}\text { Student-Centered Teacher-Centered } \\
\text { Teacher-Student Interactive }\end{array}$ & $\begin{array}{l}0.419^{*} \\
-0.060\end{array}$ & $\begin{array}{l}0.111 \\
0.113\end{array}$ & $\begin{array}{l}0.001 \\
0.616\end{array}$ & $\begin{array}{l}0.62 \\
-0.22\end{array}$ & $\begin{array}{l}0.14 \\
0.16\end{array}$ \\
\hline $\begin{array}{l}\text { Teacher-Student Teacher-Centered } \\
\text { Interactive Student-Centered }\end{array}$ & $\begin{array}{c}0.610^{*} \\
0.060\end{array}$ & $\begin{array}{l}0.126 \\
0.113\end{array}$ & $\begin{array}{l}0.000 \\
0.616\end{array}$ & $\begin{array}{l}0.13 \\
-0.16\end{array}$ & $\begin{array}{l}0.69 \\
0.22\end{array}$ \\
\hline
\end{tabular}

(*) indicates significance of mean difference at the 0.05 level.

The Tukey post-hoc tests results indicated that students' performance assessment scores of the teacher-centered approach differed significantly from student performance assessment scores of student-centered and teacher-student interactive approaches. No significant differences existed between performance scores of student-centered and teacher-student interactive methods. This is in consonance with the works of Lei, (2007) about the relationship between student-centered and teacher-student interactive methods and students' academic performances in comparison with traditional instruction showed that studentcentered and teacher-student interactive methods have a more positive impact on students' academic performances than traditional methods. This difference in academic performances of students could be attributed to the fact that Student-Centered and Teacher-Student Interactive methods are considered an effective alternative to traditional teaching methods because it presents students with unlimited opportunities to demonstrate the mastery of contents taught.

\section{Conclusion}

Teaching - learning is a process that must involve both the teachers and the students/learners and using appropriate strategies depends on the ingenuity of the teachers. It has been postulated in this work that a good teacher should be conversant with various methods of teaching so that they can use varieties of them in a classroom situation. It could also be concluded that the methods of teaching that are student - centred and the teacher - interactive methods enhance learning than that of the teacher - centred. Students build a better understanding of the main concepts more effectively when they are engaged to solve problems during class activities or teaching - learning processes. 


\section{Recommendations}

New approaches to teaching - learning processes which connect to the learning needs of students should be put in place in order to reduce the menace of students performing poorly in school and eventually dropping out of studies.

Student-centered learning environment should be encouraged in our secondary schools because it produces higher-level learning outcomes more efficiently than a traditional teacher-centered environment.

There should be no bias in the selection of teaching methods by teachers in areas in which they possess exclusive monopoly knowledge to improve students' academic performances in our secondary schools.

Teachers should create an atmosphere conducive for learning in order to enhance the development of students' learning experiences.

Moreover, teachers should also increase their knowledge of various instructional strategies in order to keep students engaged and motivated throughout the teaching learning processes.

Teachers need to understand they should embrace the use of ICTs as a way of improving the students' academic performances in our secondary schools.

There is need for training teachers on the new methods of teaching for effectiveness of the content delivery, this will help the students to improve in performance.

The Ministry of Education, Policymakers and other stakeholders should ensure that school teachers adopt new methods and strategies which are learner-centered to improve basic performances in the learners.

Policies should be formulated to ensure that schools are equipped with ICT tools to make teachers more interactive to deliver quality teaching.

Teachers need to be conversant with numerous teaching strategies/methods that take recognition of the magnitude of complexity of the concepts to teach the students. 


\section{REFERENCES}

Adunola, O. (2011).The impact of teachers' teaching methods on the academic performance of primary school pupils in Ijebu-Ode Local government area of Ogun State. Ijebu Ode:Ego Booster Books.

Atolagbe, S. A.(2020) Conference materials of the department of social studies, school of secondary education, Emanuel Alayande College of Education, Oyo June 6, $2020 .$.

Ayeni, A.J. (2011). Teachers professional development and quality assurance in Nigerian Secondary Schools," World Journal of Education, 1(2), 143-149.

Cooper, S.T. \& Cohn, E. (1997). Estimation of a frontier production function for the South Carolina Educational Process. Economics of Education Review, 16(3), 313-327.

Hake, R. R. (1998). Interactive engagement versus traditional methods: a six thousand student survey of mechanics test data for introductory physics courses. Am. J. Phys. 66, 64-74.

Hightower, A.M. (2011). Improving students' learning by supporting quality teaching: Key issues, effective strategies," Editorial Projects in Education. Available on <http://www.edweek.org/med/aperc_qualityteaching_12.11.pdf>

Lei, J.,\& Zhao, Y. (2007). Technology uses and student achievement: a longitudinal study. Computers and Education. 49(2), 284-296.

Lindquist, T. M. (1995). Traditional versus contemporary goals and methods in accounting education: bridging the gap with cooperative learning. Journal of Education for Business, 70(5), 278-284.

Tebabal, A. \& Kahssay, G. (2011). The effects of student-centered approach in improving students' graphical interpretation skills and conceptual understanding of kinematical motion, Lat. Am. J. Phy. Edu, 5(2), 374-381.

Wiggins, G. (1987). Creating a thought - provoking curriculum. American Educator, Winter, 10-17. 